\title{
O non serviam de Augusto
}

\section{Augusto's non serviam}

\author{
Kenneth David Jackson \\ Yale University, New Heaven, Connecticut, United States of America
}

\begin{abstract}
Resumo: A poesia de recusa de Augusto de Campos, na tradição do manifesto de 1914 de Huidobro, non serviam, rege o universo poético da recusa. Define uma posição de independência estética, contra a comercialização, contra a retórica tradicional e contra a poesia discursiva. Alia-se aos poetas independentes e insólitos de qualquer época que respeitam o rigor da composição. O livro mini $N \tilde{A O}$ de Augusto é expressivo de uma tensão criativa que percorre toda a obra, um negativo positivo que apoia a inovação, como as correntes de demolição praticadas pelas vanguardas históricas. Uma tensão verbivocovisual percorre a sua obra. A poesia da recusa abrange um programa estético e também social, que justifica o "anti", a "anti-poesia" e a escrita "à margem da margem," encontrado no cerne da consciência poética e social das vanguardas poéticas.
\end{abstract}

Palavras-chave: Non serviam; Recusa; Inovação; Rigor; Anti-poesia

\begin{abstract}
Augusto de Campos' poesia da recusa, in the tradition of Huidobro's 1914 manifesto non serviam, directs his poetic universe. It defines a position of esthetic independence, against commercialization, against traditional rhetoric and against discursive poetry. Augusto allies himself with independent and innovative poets of all time periods who respect the rigor of composition. His non-conformist mini-book $N \tilde{A O}$ reinforces a negative positive that supports difference, while reflecting broad currents of demolition practiced by the historical vanguards. A creative verbivocovisual tension runs throughout his works. Augusto's poetry of refusal covers an esthetic and social program that justifies the "anti," "antipoetry," and writing "on the margin of the margin" lying at the nerve center of poetic and social consciousness of vanguardist poetics.
\end{abstract}

Keywords: Non serviam; Refusal; Innovation; Rigor; Anti-poetry

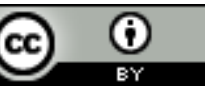


O Tempo é sim e não, o homem se multiplica, Mas o que é este Sim-e-Não ninguém explica. Paul Fleming (1609-1640) Tradução de Augusto de Campos

El poeta, en plena conciencia de sua pasado y de su futuro, lanzaba al mundo la declaración de su independencia [...] Una nueva era comienza.

Huidobro

Nunca mais servirei mortais Não mais servirei mortais Jamais servirei mortais Não servirei mortais Não servirei

Jorge de Sena, 'Sobre um verso de Sophia de Mello Breyner'

Em verdade, penso que da grande divisão das pessoas está entre as que dizem sim e as que dizem não [...] abençoados os que dizem não, porque deles deveria ser o reino da terra [...] o reino da terra é dos que têm o talento de pôr o não ao serviço do sim, ou que, tendo sido autores de um não, rapidamente o liquidam para instaurarem um sim $[\ldots]$ José Saramago, História do Cerco de Lisboa, 1989: 330

Quando o poeta chileno Vicente Huidobro (1893-1948) leu o manifesto Non serviam no Ateneo de Santiago em 1914, rejeitou a falácia patética e a Natureza como temas para a poesia. O manifesto proclamou a independência artística do indivíduo e a autonomia criativa para uma nova era ("una nueva era comienza"), declaração comum a manifestos das vanguardas históricas do novo século. O personagem Stephen Dedalus de James Joyce usou a fase non serviam no romance A Portrait of the Artist as a Young Man (1916), significando a sua recusa de servir aquilo em que não acreditava mais. Em ambos os casos, o "não" de non serviam comunicava uma mensagem positiva, um princípio estético criado de um modo inverso por uma expressão de negação e oposição, técnica encontrada comumente também nas correntes de demolição da tradição praticadas pelas vanguardas históricas.

Um século depois da leitura de Huidobro, Augusto de Campos viajou para o Chile como recipiente em 2015 do Prêmio Ibero-americano de Poesia Pablo Neruda, do Conselho Nacional da Cultura e das Artes (CNCA) e da Biblioteca Nacional do Chile. No livro o anticrítico, na introdução em verso à seção "América Latina: Contra-Boom da Poesia," Augusto reconheceu a excepcionalidade de Huidobro por trabalhar diretamente com a linguagem, no longo poema inventivo Altazor (1919). Destacou Huidobro por haver superado a “[...] insuportável retórica metaforizante" da poesia hispano-americana 
[...] e por enfocar "o núcleo das palavras / que desintegram e reconstroem / em novas vivências léxicas / e novas sondagens poéticas" (1986, p. 161-2).

De Altazor, poema desconexo e surrealista em sete cantos, Augusto traduziu um trecho da versão de 1930, feita por Huidobro em francês; num fragmento com variações inovadoras da palavra francesa rossignol, deveria ter chamado a sua atenção pela variação semântica de neologismos, que produziu uma sequência verbivocovisual de variantes, técnica semelhante à variação de não-palavras usada por poetas concretas nos anos 1950 e 1960. Entre as variantes, a forma correta de rossignol não aparece:

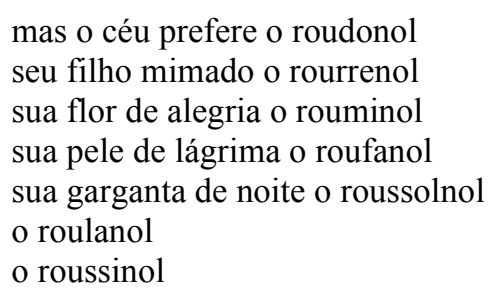

$\mathrm{Na}$ mesma seção de o anticrítico, Augusto traduziu um poema de mais concentrada negação e experimentação criativa com a linguagem pelo poeta argentino Oliverio Girondo (1891-1967), "El puro no:"

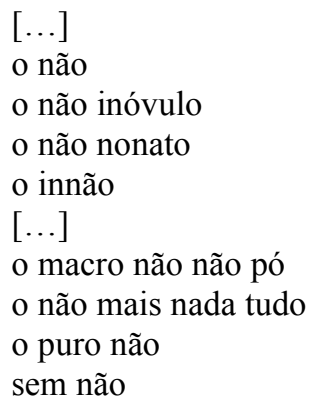

Girondo publicou o poema no seu último livro, En la masmédula (1953), no mesmo ano que Augusto publicou os poemas a cores de Poetamenos. A ensaísta Camila Torres Povea observa o uso por Girondo de técnicas derivadas das vanguardas históricas, particularmente os neologismos com que criou uma "língua dentro da linguagem" para intensificar o significado (2013, p. 158).

Com estas duas "contra-traduções," Augusto valorizou a experimentação na linguagem poética latino-americana acima do tradicional discurso retórico, de linguagem metafórica e padronizada. O título que escolheu, "Contra-Boom," toma o lado da poesia 
experimental de Huidobro e Girondo contra a popularização de romances escritos por um grupo de jovens autores hispano-americanos que lançaram uma onda de prosa sobre assuntos políticos e históricos, publicada e traduzida largamente na Europa nos anos 1960 e 1970, conhecida como "El boom."

\section{$1 \mathrm{O}$ Não e as vanguardas}

O primeiro "não" da poesia concreta se evidencia na composição não convencional, regida por uma dimensão verbivocovisual, onde o arranjo gráfico, a estrutura, o design, o som e a linguagem interagem. Na recusa de poesia discursiva existe uma diferença fundamental na constituição, comunicação e recepção do significado, por dois motivos principais: primeiro, o método criativo é aliado às outras artes e, segundo, reflete a influência de uma seleção universal sincrônica de textos e de técnicas inovadoras, contrários à tradição recebida. Assim, a leitura do poema concreto faz com que o leitor repense a informação estética e reconfigure a natureza do conhecimento pelo "não." A aparência gráfica reconfigura a questão de como se constitui um significado na poesia. As dimensões não verbais da composição -- espaço, silêncio, ausência, vazio e recusa -figuram entre outros recursos do "não," provocam diferenças no significado, efetuadas pela estrutura isomórfica. A prática do "não" gera o que William Franke (2011) chama de "registros de significação," que por sua vez estruturam o significado do poema, desafiando as normas comuns da escrita e do discurso, se opondo a elas.

O "não" da poesia concreta é um procedimento de inclusão pela exclusão, um negativo positivo que apoia a inovação, definido pelos princípios da estética concreta. Funciona neste caso como estratégia criativa, seja pela rejeição de estilos literários tradicionais, lição aprendida em outros textos de invenção, seja pela produção de significados alternativos. Da mesma maneira, alguns livros de crítica literária desafiam a norma pela posição negativa, por exemplo, Against Interpretation de Susan Sontag, ou Against Literature, de John Beverly. Adam Shellhorse amplia o termo "anti-literatura" para incluir uma reavaliação de um conceito fundamental do escritor, "repensar o que pode significar a literatura nos dias de hoje" $(2017$, p. 3$)$.

A presença do "não" na poesia concreta brasileira se evidencia tanto no âmbito da história literária, quanto no conceito e na operação do texto. O campo do "não" pode ser 
visto como contribuição à criação de um significado positivo pelo mecanismo de negação controlada, comparável às correntes amplas de demolição praticadas pelas vanguardas históricas: No "Ultimatum" do ORPHEU, por exemplo, Álvaro de Campos gritou, "Fora com isso tudo! Fora!"

No ensaio "Para uma poesia sincrônica," Haroldo de Campos cita Pound, no $A B C$ of Reading (1934), pelo método seletivo que extrai o que julga ser a melhor poesia de uma longa história diacrônica, "a drastic separation of the best from a great mass of works [...] that weigh over all others" $(1969$, p. 208). Haroldo por sua vez recomenda uma seleção sincrônica de textos inovadores, formada pela rejeição ou exclusão de modelos tradicionais a favor daqueles considerados inovadores. Pensando numa renovação de formas, Haroldo propõe uma antologia sincrônica de poesia brasileira de invenção. Da mesma maneira, o conceito de constrição nas obras do poeta Dom Sylvester Houédard exclui "the necessary negative anti-past [...] in a kind of cleansing or purging" (Thomas 2017, p. 47); esse ato é comparável à operação sincrética de Haroldo. Assim a negação e a inovação se tornam complementares, pois a negação, inerente à seleção de textos, faz parte de uma corrente alternada.

Para os poetas concretos brasileiros, o uso consciente e programático de materiais poéticos resulta de um "não" primário, uma recusa purgante da tradição, ingrediente do método crítico praticado pelas vanguardas de todos os tempos. Como elucida Haroldo: "Neste ponto cabe uma distinção fundamental entre o poema concreto e o poema surrealista. O surrealismo, defrontando-se com a barreira da lógica tradicional, não procurou desenvolver uma linguagem que a superasse [...] O poema concreto repele a lógica tradicional [...] (1975, p. 77-78). O propósito do Haroldo é defender uma posição ética, a necessidade de definir um problema exterior à lógica da forma e da linguagem, levantar questões que vão além do texto para se integrarem na "cosmovisão do homem de hoje" como valor (1975, p. 80).

\section{Setenta anos de uma poética de recusa, 1951-2021}

Com 70 anos de produção poética, numa das carreiras mais longevos em toda a literatura latino-americana, ultrapassando Carlos Drummond de Andrade, Augusto de Campos tem seguido um conjunto de princípios estruturais recorrentes, fundados numa premissa vanguardista de negação e de resistência. O non serviam de Augusto é a sua afirmação de 
fidelidade unicamente à poesia, especialmente às formas "puras" da estética concreta, exemplificadas pelo "puro no" de Girondo e pelo rossignol de Huidobro. Augusto declara a sua devoção à poesia e a seus componentes estéticos: "Minha meta é a poesia que, de Dante a Cage, é cor, é som [...]” (1986, p. 10) - e aponta Emily Dickinson como exemplo merecedor de admiração:

Preferiu o difícil anonimato a trair a poesia.

Também encontra um exemplo na "opção-estratégia” de Marcel Duchamp:

a ação na raiz das coisas / sem suportes apriorísticos: um livro ou um vidro / uma capa ou um corpo / um postal ou um disco / um dado ou um vaso / um xeque ou um cheque / ou o silêncio / mas tudo ou nada / entre o visível e o invisível / o imprevisível / choque" (1986, p. 210).

O non serviam de Augusto equivale a uma poética de recusa e de exceção, em todas as suas dimensões - estéticas, históricas, sociais e culturais - que equivale uma teoria da literatura e um programa estético abrangentes, apoiando os princípios sociais e éticas que percorrem a sua carreira inteira, sob a égide da poesia concreta. As suas posições, embora nunca proclamadas num único manifesto, se tornam aparentes quando se lê os seus prefácios, introduções e ensaios. Proclama a recusa, principalmente, como credo estético e libertário, participando da linguagem de resistência encontrada em posições vanguardistas. No seu originalíssimo "NÃOfácio" Augusto confirma que "A recusa e boa marca de poesia” (2003, p. 11).

O objetivo estético e intelectual do projeto poético de Augusto é de avançar a consciência crítica do poeta e da poesia, como declara em LINGUAVIAGEM: "Poesia como arte e como forma de conhecimento - consciência da consciência" (1987, p. 42). Vê recusa tanto na própria consciência crítica do poeta, ilustrada pelo caso de Valéry, “[...] que instaura uma realidade intelectual à margem da realidade, e até oposta a ela [...]," quanto na técnica de composição: "O rigor das recusas, a quantidade de soluções que são rejeitadas, as possibilidades que o escritor se proíbe, manifestam [...] o grau de consciência [...]”' (1987, p. 14).

Ainda mais importante é a consciência da linguagem pela experimentação com a forma, procedimento preparado pela poesia construída de João Cabral de Melo Neto e 
pela experimentação de Murilo Mendes, ao misturar prosa e poesia (Transístor, 1980). Comparte os valores de inovação, rigor formal e crítica com as múltiplas línguas e literaturas que identifica sincronicamente através do tempo. Lamenta o abandono da técnica do fazer poético ligado ao verso, exemplificada nas sutilezas de Mallarmé e Valéry: "Basta dizer que são poucos os poetas e professores de literatura que, entre nós, dominam com inteira competência as técnicas da metrificação e da versificação" (1987, p. 42). A primeira recusa é a rejeição de poesia desregrada, em favor de uma nova disciplina, com explica: [...] a poesia concreta [...] criou novas formas, rigorosas, funcionais - economia de precisão: 'Cronomicrometragem do acaso.' [...] Para além da tipologia das novas linguagens [...] foi essa postura ético-poética, levada ao limite do quase-silêncio [...] que ela ofereceu ao contexto dos anos 50 [...]" (1987, p. 41).

Verso reverso controverso, LINGUAVIAGEM, O anticrítico, À margem da margem, Poesia da recusa são todas antologias em que Augusto apresenta poesia mundial inovadora em tradução. Escolhe poetas que precisam passar de alguma maneira pela peneira da recusa poética e estética. Dos poetas escolhidos para poesia da recusa, diz:

Os poetas aqui reunidos, por diferentes que sejam entre si, têm em comum a bandeira da recusa. Nem todos os poetas apresentados neste livro pertencem estritamente à categoria dos “inventores", os descobridores de novos procedimentos artísticos, privilegiados nas minhas aventuras tradutórias. Mas todos eles são extraordinários artífices do ofício poético, com os quais há muito que aprender [...] seja pela linguagem seja pela postura ético-estética. (2006, p. 16)

As suas traduções entram numa aliança com as literaturas mundiais, num espírito de resistência e de inovação. Aonde mais neste mundo é que se encontra a poesia de Crane, Thomas, Stevens e Stein ao lado de Blok, Mandelstam, Akhmátova, Iessiênin e Tzvietáieva?

\section{As vanguardas históricas}

A poética de Augusto sempre foi guiada por postulados vindos de muitos dos principais autores e movimentos de vanguardas artísticas e literárias, muitos dos quais Augusto chegou a conhecer intimamente, seja como cofundador da poesia concreta, por correspondência com Ezra Pound e outros teóricos da modernidade, por anos de estudo, 
patente em muitos ensaios eruditos, ou como tradutor de Pound, Joyce, Stein e outras das figuras principais da poesia modernista. Augusto comparte as qualidades de independência e autonomia encontradas no manifesto de Huidobro; não resta dúvida de que a poesia de recusa está matizada de intenções revolucionárias vindas dessas vanguardas. A antologia, poesia da recusa, confirma a intenção de criar um impacto revolucionário, quando proclama: "A poesia requer de nós algum instinto revolucionário, sem o qual ela não tem sentido" (2006, p. 17). Augusto aponta o caso do poeta francês Tristan Corbière (1845-75), como exemplo de um "poeta antipoético [...] a modo de guerrilha" (1986, p. 10). E nos seus ensaios, emprega frequentemente a linguagem dos manifestos: "Contra a crítica para críticos [...] ainda que isso nos custe mais antipatias e mais incompreensão" (1978, p. 88-9). Denuncia claramente o tipo de poetas e de poesia que rejeita:

O que abomino [são] os que não iluminam nem se deixam iluminar. Os desconfiados e os ressentidos [...] (1986, p. 10); Os futurocratas passadófobos, que dividem a história em antes e depois de si próprios, não passam de medíocres narcisistas que já vão ser enterrados no próximo passado do futuro." $(1978$, p. 8)

Na sua lista de negativas figura o "bloqueio massacrante / do dilúvio informativo," ao lado da “[...] inanidade dos poemas 'abertos', mas sem estrutura e sem know-how" (1987, p. 41).

\section{A independência estética do poema}

Desde a série de poemas às cores Poetamenos, Augusto separa o poeta da obra e desacopla a criatividade do eu lírico. A construção poética opera nos bastidores, para que os materiais tenham um papel e uma presença autônomos, não determinados pela voz de um poeta. Em Poetamenos, por exemplo, Augusto constrói a sua "língua dentro da linguagem" estruturando múltiplas camadas de fragmentos de palavras e de cores espaçados uma "melodia de timbres," comparáveis à montagem de um desenho que harmonize com o conceito de Anton Weber de klangfarbenmelodie, visto no poema Lygia fingers: 


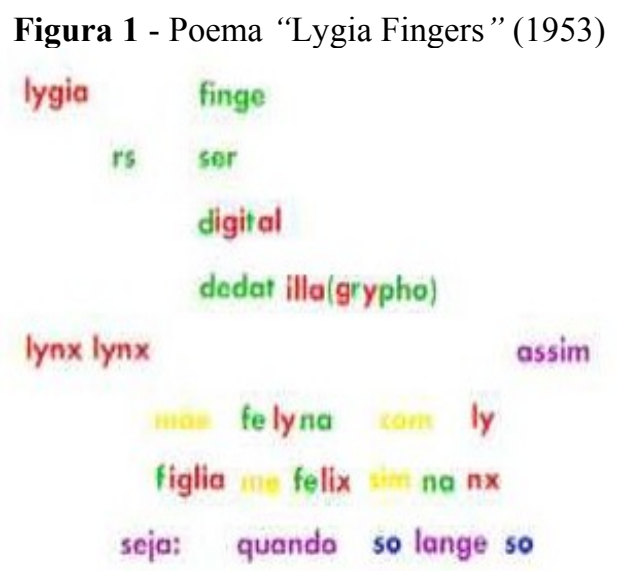

Fonte: Site oficial de Augusto de Campos

Enquanto Huidobro domina o leitor diretamente com a voz do poeta, Augusto prefere que a obra opere autonomamente. A poesia brasileira fora separada definitivamente das construções retóricas pela poética modernista dos anos 1920 e 30, pelo apelo à fala popular, ao humor, à sátira e à introspecção. Aprendendo mais diretamente da poética construtiva de João Cabral de Melo Neto, depois de Pound e as vanguardas internacionais, a posição de Augusto sobre a linguagem poética concentra na materialidade estética do poema. É o trabalho que é autônomo e não o poeta. Ao usar a linguagem das formas, o poeta consegue expressar aquilo que não pode ser dito diretamente em palavras: "Entre falar e calar, seus poetas parecem dizer o indizível, por não tentar dizê-lo, mas realiza-lo através da linguagem” (2003). João Cabral ficou impressionado com os poemas de Augusto, como miniaturas plásticas: "Certa vez João Cabral, em conversa comigo, e para minha surpresa, me disse que a minha poesia lembrava a ele a arte miniaturizada de Paul Klee. Cada poema era único, diferente do outro" (2003, p. 11).

\section{5 ЯEVЕЯ: Palavras-Objetos no Espaço-Tempo}

A exibição ЯEVEЯ em São Paulo em 2017 reuniu trabalhos representando 65 anos de produção, desde livros a colagens e instalações usando letras, palavras, imagens e sons. Os " $R$ " invertidos obrigaram o observador a ler de maneira diferente e de estar consciente da linguagem não-ortodoxa, invertida, mesmo sendo de fácil leitura. O estudioso John Piccione sugere uma comparação entre a epistemologia barroca do paradoxo, da 
deslocação e do disfarce e uma tensão negativa comparável na poesia concreta $(2009$, p. 61-70). Haroldo de Campos foi o primeiro a falar da obra aberta de arte como "neobarroca," ou na frase de Pierre Boulez, "um barroco moderno" (1973, p. 33). Comparável à frase de Haroldo nas Galáxias, nunhunzinho de nemnada nunca, o non serviam comunica uma tensão neobarroca negativa que oscila entre uma visão construtivista e cosmopolita universal e uma confrontação com a sociedade e a tradição.

Poesia da reusa é uma re-escrever consciente, um barroco moderno, na expressão de Marjorie Perloff, uma “arrière-garde.” Numa operação de ЯEVEЯ o poema-objeto ("palavra-coisa no espaço-tempo" é a formula da Teoria da Poesia Concreta), Augusto desconstrói e reconfigura o lugar comum "tudo está dito" (2005, p. 222), numa operação que o ensaísta Adam Shellhorse chama de implosão:

\begin{abstract}
In [...] Augusto de Campos's video-poem, “tudo está dito" (everything's said) (1979; 1996), by accounting for literature's nonrelation to identity, we witness how anti-literature proposes a new conception of form where the conventional literary "all said" becomes undone: "tudo / está / dito / tudo / está / visto / nada / é perdido / nada / é per / feito / é sói / mpre / visto / tudo / é / infi / nito" (every / thing's / said / every / thing's / seen / nothing's / lost / nothing's / per / fect / it's only / unforeseen / everything's / infi / nite). In effect, through the antipoem's zigzagging movement across the verbal and nonverbal, the poem and video, the straight line and labyrinth, we witness the idea of literary evolution and plenitude - everything's / said / everything's / seen-implode as a selfcritical field of limitless verbal, vocal, and visual force. (2017, p. 166)
\end{abstract}

A recusa diz respeito à tensão de um contraponto barroco com o seu contrário, ou inverso: uma suspensão das regras, oscilação entre concreto e abstrato, racional e irracional, mecânico e fluido, aleatório e planejado, som e silêncio, fragmento e impressão, inconsciente e conformista. Esses opostos agem em contraponto: de um lado o abstrato vira concreto, no outro o concreto se torna magicamente, por assim dizer, imaterial, "desaparecendo em puro ar" (2012, p. 183-92). Augusto reconhece a confluência de contrários, a tensão isomórfica que emana da negação positiva da recusa: "Saber ver e ouvir estruturas será pois a chave para a compreensão de um poema concreto" (1975, p. 80). A leitura da poesia concreta exige a compreensão da negação, de como e por quê se nega. 


\section{Traduzir literaturas mundiais}

A recusa de Augusto consiste de uma paideuma de autores e de obras de invenção, selecionados de épocas diversas das literaturas e línguas mundiais. Como escreve em VERSO REVERSO CONTROVERSO, "O antigo que foi novo é tão novo como o mais novo novo. O que é preciso é saber discerni-lo" [...] (1978, p. 7). Na antologia Poesia da recusa Augusto define uma arte poética universal fundada na inovação e rigor formal: "A poesia é uma família dispersa de náufragos bracejando no tempo e no espaço [...] os que lutaram sob uma bandeira e um lema radicais -- a invenção e o rigor” (1978, p. 8). A tradução criativa é, ainda, uma forma de crítica dirigida, como explica Augusto em textos dos anos 1970 e 1980: “Outrossim, ou antes, outronão: tradução é crítica, como viu Pound melhor que ninguém" (1978, p. 7). Ao revelar o novo, a tradução crítica expõe o rotineiro: “[...] crítica de amor e de amador [...] crítica via tradução criativa - dirige a seta do seu 'anti'” (1978, p. 7; 1986, p. 10).

O non serviam de Augusto é codificado na introdução à antologia de tradução poética, poesia da recusa (2006), que é uma forma de crítica. A recusa foi critério principal na seleção dos poetas; com essa peneira, procurou especificamente duas qualidades principais: "descobridores de novos procedimentos artísticos" e "extraordinários artífices do ofício poético" (2006, p. 16), ou seja, inovação e rigor. A recusa, ou resistência, seja estética ou ética, é o filtro por que a melhor poesia moderna deve passar como "baluarte contra o fácil, o convencional e o impositivo" (2006, p. 15). Essa exigência faz com que cada poema representa o limiar das possibilidades de criação: "Cada poema é como se fosse o último e ressoa, inevitavelmente, o fracassucceso desse conflito [...]" (1994)

A poesia que sobrevive a peneira da recusa se torna imune da "cosmética cultural," junta-se a um coro de vozes dissonantes, unindo o tempo, as línguas e as suas diversas formas radicais de recusa. Segundo Augusto, dão novo sentido à marginalidade, “[...] dos que buscam caminhos não balizados, abrindo sendas novas [...] Do avesso do avesso à margem da margem" (1989, p. 7). Descreve o novo caminho avesso procurado pela poesia de recusa, cujo objetivo é animar a substância da poesia. Apresenta ao leitor poemas novos e insólitos que descobre, como "Julia's Wild," de Louis Zukovsky, e os poemas óticos pouquíssimo conhecidos de Bob Brown. 
Nas suas traduções, Augusto sempre procurava resgatar a escrita criativa de períodos históricos e línguas diversos, assim em o anticrítico Huidobro e Girondo se juntam a um panorama de poetas criativos mundiais, desde Dante a Gertrude Stein. Augusto recapitula o desafio estético ao qual Baudelaire dá voz: "Quand sera-t-on artiste, rien qu'artiste, mais bien artiste?" e ao mesmo tempo aplicando uma crítica perspicaz: "Não sou—nem poderia ser-contra a crítica inteligente, a iluminadora [...] cujas reflexões sobre arte e sobre poesia constituem para mim fonte permanente de estímulo e inspiração (1986, p. 10). É um caminho difícultoso e desconfortável para tentar, “[...] a sofrida experiência da recusa poética" $(2006$, p. 17) porque poucos são aqueles que escolhem seguir a ética estreita da recusa (1987, p. 41).

Os 13 poetas escolhidos para a antologia poesia da recusa - classificados de "irmãos no tempo" - satisfazem alguns requisitos essenciais: recusam e inovam ao mesmo tempo, mostram integridade ética e estética e mantém o espírito de diversidade, “Dispares. Diversos. Dispersos" (1978, p. 7). Os poemas, pelas suas qualidades insólitas, resistem tradução. Augusto os distingue por serem "poemas que [...] efetivamente continuam poemas depois de traduzidos" (1989, p. 17), unificados pela "bandeira da recusa," seja por razões de misticiso rebelde, ousadia vanguardista, imaginação atemporal ou sátira blasfema. Nessa questão de irmandade, recusa e inovação interagem como um par, "de modo a causar alterações na função da imagem de acordo com as questões culturais de cada época" (Projéctica, 2012, p. 191). A partir do misticismo rebelde o poeta barroco alemão Quirinius Kuhlmann (1651-1698), a antologia apresenta artesãos da poesia com qualidades irregulares e imprevistas, desde Mallarmé a Gertrude Stein, Yeats e Pound a Dylan Thomas, Wallace Stevens a Hart Crane, Maiakovsky a Mandelstam.

\section{Contra a comercialização, conformismo, massificação}

Um senso de ética leva Augusto a uma forte rejeição de comercialização, conformismo e massificação na comunicação e nos relacionamentos sociais. Como os poemas mundiais que traduz, a sua poesia retrata e responde ao nosso tempo dentro da estética concreta; contribui a um ponto de vista que enfrenta qualquer status quo com "[...] formas de desacordo com a sociedade ou com a vida [...]" $(2006$, p. 15). 
Os títulos dos livros de Augusto frequentemente realçam a sua posição ética contra as normas e práticas de comercialização, conformismo, mercantilização e massificação atuantes na sociedade contemporânea. Concebeu muitas destas obras na década de 1960, numa época quando São Paulo está começando a sua trajetória de uma cidade de uns poucos milhões de habitantes a uma cidade de mais de 20 milhões em 2021. Enfrenta os primeiros anos da ditadura militar. Há problemas sociais concomitantes que acompanham o crescimento, estimulando novos poemas que na leitura de Adam Shellhorse "explicitam 'objetos' políticos [...] que incluem, mas não limitados ao problema da fome subalterna, a reforma agrária, a propaganda capitalista, o bombardeamento de Hiroshima e a Revolução Cubana" (SHELLHORSE, 2017, p. 87).

$\mathrm{O}$ artista Arnaldo Antunes nos oferece um sumário da longa trajetória de recusa social, cultural e literário de Augusto ao se referir a uma sequência de prefixos e conjugações, tirados dos seus títulos, que afirmam pela negação: "Do menos ao ex, do ex ao des, do des ao não, a poesia de Augusto renova a sua afirmação" (Não, 2003). Muitos dos títulos de livros de Augusto incluem formas diversas do non: "poesia da recusa," “anti-poesia” and a escrita “à margem da margem." Já na primeira fase da poesia concreta, estando no Brasil, Jorge de Sena referiu à experiência dos poetas concretos como uma “escola de anti-retórica" (1963, p. 127), reparando que as formas marginais da criação literária que preferiam eram de alguma maneira marginais quando consideradas na panorama ampla de uma literatura (1989, p. 15). Atraiu a atenção de Augusto, nesse sentido, Marcel Duchamp, pela forma muito particular de marginalidade: "Ninguém como ele se desligou tanto da ideia de 'obra"” (1986, p. 202). Como ato "anti," Augusto coloca um "não" no núcleo da consciência poética e social da poesia concreta na primeira fase da sua evolução:

Do outro lado do outro lado à margem da margem [...] vêm vozes singulares capazes de perturbar a toada e o coro monótonos [...] Se estes são inevitáveis e dão o tom geral da era, de algumas vozes dissonantes minoritárias, pode provir, subitamente, uma luminosidade inadvertida que desbanalize o som, varre o marasmo e sacuda o tediário cotidiano [...]. (1989, p. 9).

O título misterioso da primeira revista literária da poesia concreta em São Paulo na década de 1950, Noigandres, de um poema do trovador Arnaut Daniel, pensa-se que significa "contra o tédio." Assim, Augusto aponta a sua recusa contra o tédio, a mediocridade e a retórica vazia. 
Ná década de 1960, por exemplo, Augusto respondeu diretamente a questões sócio-políticas com formas originais. Os poemas chamados de Popcretos, exibidos na Galeria Atrium em dezembro de 1964 (com obras de arte por Waldemar Cordeiro) incluíram GOLDwEATER, Olho por Olho, Psiu! e SS (Ssemântica das Ssiglas). A sua posição "contra” também vive nos poemas-cartazes LUXO-LIXO (1965), inspirado pela exibição na Atrium, e VIVA VAIA (1972), referência à fala de Caetano Veloso diante de uma plateia hostil numa performance em São Paulo. Os dois poemas estão ligados à cultura jovem, à resistência contra o regime e à confrontação de uma sociedade conservadora, hoje ícones da história e da modernização da cidade de São Paulo.

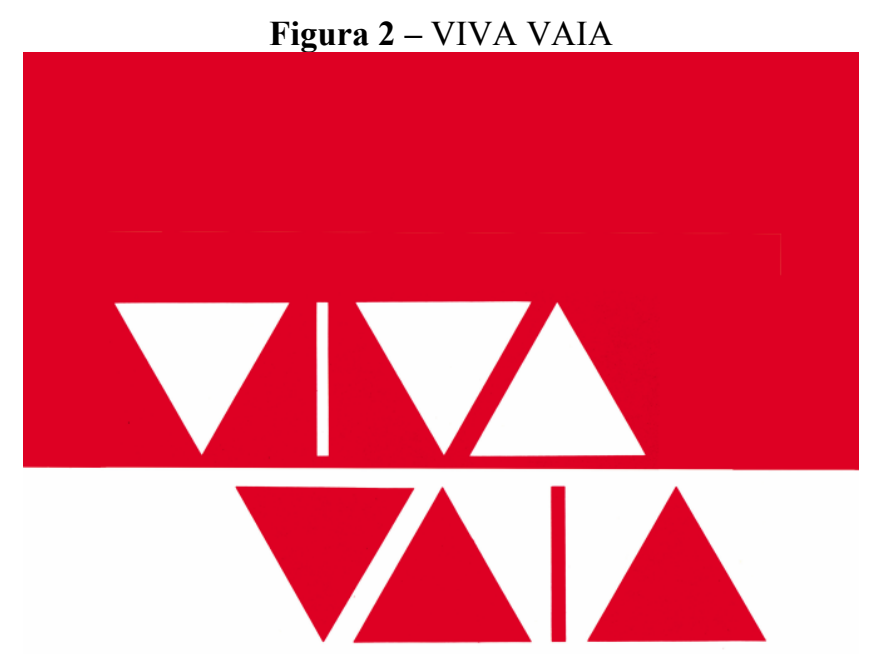

Fonte: Augusto de Campos

\section{NÃO}

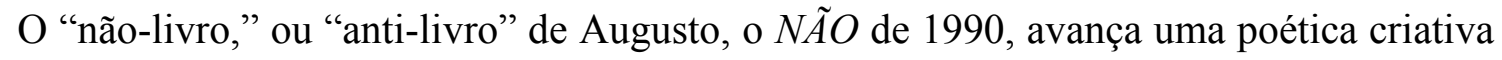
dirigida contra os livros convencionais, mesmo se o livro como forma é inescapável: "Mas o livro [...] é embalagem inelutável, ainda mais para os guetos e guerrilhas da poesia e suas surdas investidas catacúmbicas" (2003, p. 11). Medindo 5 X5 cm, 14 páginas finas grampeadas duas vezes no lado esquerdo, o anti-livro Não consiste de colunas de letras, ou seja não-palavras datilografadas, que só podem ser lidas por quem entende a estratégia de desbloquear o sentido da leitura. Como se zombando de livros publicados, 
cada "volume" desta edição é numerado e assinado pelo autor. A própria composição de Não é uma recusa a colaborar com a indústria editorial, uma preferência artesanal que percorre o repertório poética de Augusto, desde a primeira publicação, $O$ Rei menos $o$ Reino (1951), às revistas Noigandres, Invenção e os poemas a cores de Poetamenos, verdadeiros projetos artesanais feitos nas gráficas. Desde cedo, esses títulos abriram um caminho paralelo à das publicações pela Editora Perspectiva e outras grandes editoras que chegariam a partir da década de 1960. Os “anti-livros" artesanais, porém, distinguem a sua carreira poética, sobretudo as traduções feitas à mão pela Noa Noa de Cleber Teixeira, em Florianópolis, aos recentes pequenos volumes de tradução poética, impressos pelas Edições Galileu, de Londrina, Paraná, ou pela Demônio Negro, de Vanderley Mendonça em São Paulo.

Não é o supremo "não-livro" de poesia, fino, fabricado de papel simples cortado à mão em quadrados; ao mesmo tempo, é uma lição, no modo negativo, de versos que ainda não chegaram ao verdadeiro estado de poesia; é uma crítica irônica e descrente a tudo que se publica sob o rótulo de poesia. A seguir a capa e página-rosto, encontra-se a primeira das 12 páginas restantes, sendo 9 de poesia, em forma de retângulo de cinco linhas, datilografadas, 10 caracteres por linha. As linhas formam uma sequência caótica e aparentemente ilegível de letras. Cada página sucessiva tem menos um caráter na última linha vertical, até chegar à uma só coluna de caracteres com leitura única, de cima para baixo. Os caracteres têm um tal arranjo e as linhas uma separação para que quase não apareça nenhuma palavra por inteiro ou reconhecível. Embora os blocos de letras tenham uma aparência caótica, há uma razão sinuosa escondendo a leitura, exemplo da natureza hermética da poesia, um toque neobarroco. A chave da leitura ziguezague leva ao desvendamento do seguinte texto:

1. meu amor dor não é poesia amar viver morrer ainda não é poesia

2. escrever pouco ou muito calar falar ainda não é poesia

3. humano autêntico o sincero mas ainda não é poesia

4. transpira todo o dia mas ainda não é poesia

5. ali onde há poesia ainda não é poesia

6. desafia mas ainda não é poesia

7. é quase poesia mas

8. ainda não é p

9. oesia 
A poesia existe no código escondido, entre as linhas, no meio das linhas, dando a impressão de incompletas e alienadas na sua ilegibilidade, de uma pura forma externa, disfarçando o significado, como se fosse núcleo oculto de um estado mais perfeito, uma iluminação. E o texto, quando lido, versa apenas sobre tudo aquilo que não é poesia, dando mais um sentido ao título, Não. O leitor precisa aprender a ver e a ler diferentemente, com insight e preparado para o inesperado, que é a condição da poesia verdadeira que se esconde: "oesia" em lugar de "poesia."

Por ter desafiado as grandes editoras, e pela sua construção insólita, Não é hoje objeto de colecionador e raridade bibliográfica, como tem sido o caso de tantas obras efémeras das vanguardas históricas. Em 2013, aproveitando a sensação que o livro em miniatura criou nos anos 1990, Não foi incorporado num livro comercial, com ensaios e foto-fac-símile do original, agora fetichizado. Mas não é o Não, não é não.

Figura 3 - Não, de Augusto de Campos

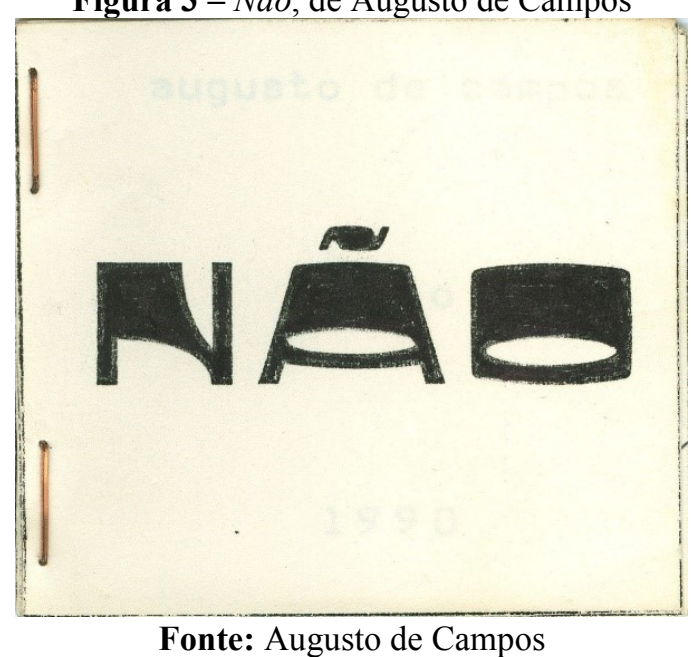

\section{A recusa que ensina}

A antologia poesia da recusa, como a afirmação implícita na sua premissa negativa, comunica principalmente pelas formas do seu non/não, como conclui Antunes: "Dessa condição limítrofe surgem as marcas de negação que vêm caracterizando sua poesia há muitos anos [...] Tais sinais de menos adquirem positividade na medida em que os poemas se efetivam, minérios extraídos de recusas a todas os excessos e facilidades" (2003, p. 90). A poesia de Augusto de Campos é uma forma contemporânea de conhecimento, em função da recusa, dimensão negative-positiva da composição concreta. Reposiciona e transforma as plataformas das vanguardas históricas num contexto mais universal e mais 
sincrônico, relacionados ao conceito de literatura mundial. Como atesta Marjorie Perloff, "o movimento concreto sempre enfatizou a transformação da materialidade em si" (2007). E pela afirmação da sua recusa, sempre sustentou o ínvio e difícil caminho para sobreviver e escrever poesia no mundo contemporâneo: "Desviagens da poesia que [...] é uma viagem ao desconhecido via linguagem" (1987, p. 7). O poeta Augusto de Campos, na véspera dos seus 90 anos, que tenho a honra de comemorar aqui, continua a nos ensinar o caminho "contra," que leva ao saber, que sabe e ensina, surpreendentemente, pelo seu "Não."

\section{Referências}

BEVERLY, John. Against Literature. Minneapolis: U. Minnesota Press, 1993.

CAMPOS, Augusto de. À Margem da Margem. São Paulo: Companhia das Letras, 1989.

CAMPOS, Augusto de. O anticrítico. São Paulo: Companhia das Letras, 1986.

CAMPOS, Augusto de. despoesia. $2^{\mathrm{a}}$. edição revista. São Paulo: Perspectiva, 2016.

CAMPOS, Augusto de. Linguaviagem. São Paulo: Companhia das Letras, 1987.

CAMPOS, Augusto de. Não. Edição particular, 1990.

CAMPOS, Augusto de. NÃO poemas. São Paulo: Perspectiva, 2003.

CAMPOS, Augusto de. Outro. São Paulo: Perspectiva, 2015.

CAMPOS, Augusto de. poesia antipoesia antropofagia. São Paulo: Cortez \& Moraes, 1978.

CAMPOS, Augusto de. poesia da recusa. São Paulo: Perspectiva, 2006.

CAMPOS, Augusto de. verso reverso controverso. São Paulo: Perspectiva, 1978.

CAMPOS, Haroldo de. A Arte no Horizonte do Provável. São Paulo, Perspectiva, 1969.

CAMPOS, Haroldo de. Galáxias. São Paulo: Editora Ex Libris, 1984.

CAMPOS, Haroldo de. Os melhores poemas de Haroldo de Campos. Seleção de Inês Oseki Dépré. São Paulo: Global, 1992.

CAMPOS, Haroldo de. A obra de arte aberta. Teoria da Poesia Concreta. São Paulo: Duas Cidades, 1975, p. 30-33. Pub. Diário de São Paulo (7 mar. 55). 
CAMPOS, Haroldo de. "Poesia concreta - linguagem - comunicação." Teoria da Poesia Concreta. São Paulo: Duas Cidades, 1975, p. 70-85. Pub. Jornal do Brasil, Suplemento dominical (28 abr. 57; 5 maio 57).

CAMPOS, Haroldo de. "A temperatura informacional do texto." Teoria da Poesia Concreta. São Paulo: Duas Cidades, 1975, p. 136-148. Pub. Revista do Livro, v. 18 n. 5,1960 .

CAVALCANTE, Ana Luísa; BARROS, Vanessa; ROCHA, Paula; PEREIRA, Francisco; PERASSI, Richard; REMOR, Carlos. Epistemologia da imagem: o concreto, o abstrato e a metáfora das imagens da organização. Projética: Revista Científica de Design, v. 3, n. 1, 2012, p. 183-192.

GÓMEZ, Isabel. Anti-Surrealism? Augusto de Campos 'Untranslates' SpanishAmerican Poetry. Mutatis Mutandis, v. 11, n. 2, 2018, p. 376-399.

MENDES, Murilo. Transístor: Antologia de Prosa, 1931-1974. Rio de Janeiro: Nova Fronteira, 1980.

PERLOFF, Marjory. Writing as Re-Writing: Concrete Poetry as Arrière-Garde.

Ciberletras, v. 17, 2007.

PICCHIONE, John. Baroque Poetry in Italy: Deception, Illusion, and Epistemological Shifts. In: BOLDT-IRONS, Leslie; FEDERICI, Corrado; VIRGULTI, Ernesto. (Orgs.). Disguise, Deception, Trompe-l'oeil. New York: Peter Lang, 2009. p. 61-70.

SENA, Jorge de. A literatura inglesa. Lisboa: Cotovia, 1989.

SENA, Jorge de. Metamorfoses. Lisboa: Moraes, 1963.

SHELLHOUSE, Adam. Anti-literature: the politics and limits of representation in modern Brazil and Argentina. Pittsburgh: U. Pittsburgh Press, 2017.

SONTAG, Susan. Against Interpretation. London: Vintage, 1994.

TORRES POVEA, Camila. ¡El NO, no significa nada! Herencia, v. 14, n. 4, 2013, p. $157-60$.

Recebido em: 30 de setembro de 2021

Aceito em: 01 de dezembro de 2021

Publicado em dezembro de 2021

Kenneth David Jackson

E-mail: k.jackson@yale.edu

ORCiD: https://orcid.org/0000-0001-9791-1588 